\title{
Characterization of Hilly Chickens in Consideration of Climate Change Factors: Light and Heat
}

\section{-Author(s)}

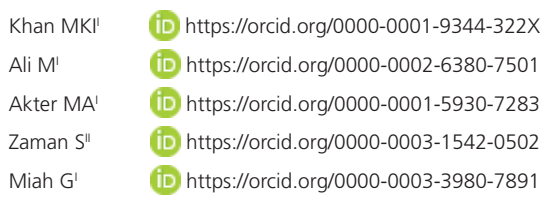

(iD) https://orcid.org/0000-0003-3980-7891

Dept. of Genetics and Animal Breeding.

Dept. of Dairy and Poultry Secience.

\section{ABSTRACT}

Hilly chickens were characterized from January 2015 to September 2016 considering climate factors (light and heat). The experimental birds were divided into three groups (heat stress; light and control). The heat was generated in the chicken's shelter by a black shaded light (Lantern) for two to three hours more after sunset. A lighting device (Lantern) was kept in the chicken's shelter for the same period for increasing daylight duration. The individual chicken's egg production, egg weight and mature live weight were studied from onset of egg production. It was observed that reddish brown hilly type chicken produced more (100.80 no/year/chicken) and larger sized (43.21g) eggs than spotted chicken (83.4 no/year/chicken and 40.46g). Among the three treatments, the lighting group produced 7.71 and 5.60 more eggs than the control and heat stress group, and one hour lighting lengths increased egg production 4 to $5.8 \%$. Fifty-five blood samples were collected, and DNA was isolated from whole blood. For genetic characterization, 10 microsatellites markers from FAO recommendation list were used in this study. PCR amplification was performed in an MJ PTC-200 Peltier Thermal Cycler. The gene flow among breeds and genetic differentiation was assessed by computing between-breed genetic parameters: molecular co-ancestry (fij). It was found that genetic diversity of these two types of chickens was moderate. Results indicated that they were originated from the same ancestor. Therefore, priority should be given for implementation of appropriate breeding programme and strategies are necessary to avoid loss of genetic diversity.

\section{INTRODUCTION}

The effects of heat stress on broilers and laying hens are reduced growth and egg production with decreased poultry meat and egg quality. Locus et al., 2013; and Star et al. (2008) reported a reduction of $31.6 \%$ in feed conversion, $36.4 \%$ in egg production, and $3.41 \%$ in egg weight in laying hens subjected to heat stress. Similar findings were reported by Deng et al. (2012) for heat stress on laying hen. Daylight has positive effects on feed intake and egg formation, which leads to the increase live weight and more eggs (Nayak et al., 2015). However, in Bangladesh, there are still some remote areas where no electricity supply is available.

The phenotypic performance studies (Khan et al., 2004, Khan et al., 2007, Faruque et al., 2010) suggested that the hilly chickens are comparatively better than other native chickens. Although the genetic characterization study using microsatellite marker of different native chicken's populations are available in the literature (Fonteque et al., 2014, Nedup et al., 2012, Zanetti et al., 2010) however, these literatures lack information on hilly chickens of Bangladesh. 
The genetic diversity of chicken genetic resources provides the basis for genetic improvement in order to increase productivity (Tixier-Boichard et al., 2009, Boettcher et al., 2010). Moreover, the understanding of the constitution of breeds, effective management and traceability of breed origin is needed for potential utilization of the genetic resources (Dalvit et al., 2007, Nakamura et al., 2010). Therefore, the current study was conducted with the objectives to characterize hilly chickens in consideration of climate change factors and to select the best genotypes of hilly chickens for further genetic improvement.

\section{MATERIALS AND METHODS}

The research work was conducted at the Animal Genetics/Poultry Research and Training Centre (PRTC) laboratory at Chittagong Veterinary and Animal Sciences University and the Chittagong Hill Tract (CHT), Bandarban district of Bangladesh from January 2015 to September 2016. The chickens and farmers were categorized per the phenotypic and morphological features of the chickens. The chosen hilly chickens were identified and kept in the farmers' households. The selected chickens were maintained by providing supplementations of concentrate feed (50g/chicken/ day) containing $2700 \mathrm{kcal} / \mathrm{kg}$ and 15.5 percent crude protein. The feed ingredients used were broken corn $(38 \%)$, broken wheat (26.50), rice polish (16\%), soybean meal (14\%), oyster shell (5\%) and salt (0.5\%). These feed ingredients were selected by allowing the chickens to scavenge the surrounding of the farmer's house where they pickup their required feed. If there were any deficiencies of energy, protein, calcium and phosphorus that were filled up from the supplements. The supplementary feeds were supplied to the farmers twice in a month, from the commencement up to the end of the study. The farmers offered these feed ingredients twice a day (morning and afternoon) to the experimental chickens in a temporary bamboo made fenced guard. For the remaining period the chickens were allowed to scavenge the surroundings of the farmer's house. The selected farmers were trained for poultry rearing in two months interval.

The selected chickens were divided into three treatment groups (heat stress, light and control). The egg production potential under these treatments were studied from April to September. Fifteen farmers were selected for each treatment group and each treatment having 30 layer chickens. The average temperature during April to September was $27^{\circ} \mathrm{C}$ from April to
September. The heat was generated in the chicken's shelter by providing a black shaded light (Lantern) for 2 to 3 hours more after sunset and the temperature was increased by $2^{\circ} \mathrm{C}$. A lighting device (Lantern) was kept in the chicken's shelter for 2 to 3 hours more after sunset in order to increase the duration of daylight. The control group was maintained for posterior comparison of the effects of heat stress and light. For light and control group the normal ambient temperature was maintained.

For all treatment groups, from the onset of egg production, the egg production and other traits of the individual chickens were recorded and monthly egg production, yearly egg production, mature live weight, egg weight and clutch size were calculated. More than 40 weeks aged chickens were considered as mature chicken.

For genetic characterization, 40 blood samples from both hilly type chickens under three treatment groups (control, light and heat stress) were collected from the jugular vein in a microtube containing $0.5 \mathrm{M}$ EDTA (as an anticoagulant). DNA was isolated followed by a protocol of PureLink ${ }^{\circledR}$ Genomic DNA Kit from whole blood samples. Extracted DNA samples were stored at $-20^{\circ} \mathrm{C}$ until subsequent use as a template for Polymerase Chain Reaction (PCR).

Ten microsatellite markers from the list of recommended microsatellites for chicken by the ISAG/ FAO were used to amplify the microsatellites regions in the chickens' genome (Table 1). A total of $25 \mu \mathrm{l}$ polymerase chain reactions (PCR) composed of 12.5 $\mu$ S Supermix, $2.5 \mu \mathrm{M}$ primers (forward and reverse), buffer $5 \mu \mathrm{l}$ and $2.5 \mu \mathrm{l}$ DNA template were prepared (Invitrogen ${ }^{T M}$ ). The PCR amplification was conducted in an MJ PTC-200Peltier Thermal Cycler or a Bio-Rad C 1000 Thermal Cycler with initial denaturation at $94^{\circ} \mathrm{C}$ for 5 minutes followed by 40 cycles of denaturation at $94^{\circ} \mathrm{C}$ for $30 \mathrm{~s}$, annealing for $30 \mathrm{~s}$ at the optimized temperature (Amie Marini et al., 2014), and extension at $72^{\circ} \mathrm{C}$ for $30 \mathrm{~s}$, and a final extension at $72^{\circ} \mathrm{C}$ for 10 minutes. The PCR products were electrophoresed on $2 \%$ agarose gel (Lonza USA) at $90 \mathrm{~V}$ for 1.5 to $2 \mathrm{~h}$ and stained with ethidium bromide. The microsatellite banding patterns were visualized on a UV transilluminator and photographed.

\section{Statistical analysis}

The total number of alleles, average number of alleles per locus across breeds and genetic diversity of the studied breeds was assessed by computing the observed $\left(\mathrm{H}_{\mathrm{o}}\right)$ and expected $\left(\mathrm{H}_{\mathrm{E}}\right)$ heterozygosity within population between breeds. Furthermore, the diversity 
Table 1 - Microsatellite markers and their sequence with corresponding fragments size, average number of alleles and annealing temperature/sec.

\begin{tabular}{|c|c|c|c|c|c|}
\hline SI. No. & Primer & Sequence & Fragments size (bp) & Number of alleles & Annealing Temp. $\left({ }^{\circ} \mathrm{C}\right)$ \\
\hline 1 & ADL0112 & GGCTTAAGCTGACCCATTAT & 120 to 134 & 1 & 60 \\
\hline 2 & ADL0268 & CTCCACCCCTCTCAGAACTA & 102 to 121 & 2 & 58 \\
\hline 3 & MCW0014 & TATTGGCTCTAGGAACTGTC & 166 to 189 & 2 & 62 \\
\hline 4 & MCW0034 & TGCACGCACTTACATACTTAGAGA & 212 to 246 & 2 & 62 \\
\hline 5 & MCW0069 & GCACTCGAGAAAACTTCCTGCG & 158 to 176 & 1 & 60 \\
\hline 6 & MCW0081 & GTTGCTGAGAGCCTGGTGCAG & 143 to 155 & 2 & 60 \\
\hline 7 & LEI0166 & CTCCTGCCCTTAGCTACGCA & 251 to 261 & 1 & 58 \\
\hline 8 & LEI0094 & GATCTCACCAGTATGAGCTGC & 251 to 283 & 2 & 58 \\
\hline 9 & MCW0248 & GTTGTTCAAAAGAAGATGCATG & 213 to 245 & 1 & 62 \\
\hline 10 & MCW0295 & ATCACTACAGAACACCCTCTC & 86 to 102 & 2 & 58 \\
\hline \multicolumn{4}{|c|}{ Average } & $1.6 \pm 0.52$ & $59.8 \pm 1.75$ \\
\hline
\end{tabular}

Source: (FAO, 2007; Nassiri, 2007 and Zanniti et al. 2010).

was calculated by the polymorphic information content (PIC) according to Botstein et al. (1980). The gene flow among breeds and genetic differentiation was assessed as Caballero and Toro, (2002) by computing the following between-breed genetic parameters: molecular co-ancestry (fij).

Least square means were estimated for all the parameters according to treatments and chicken types were analyzed by Proc GLM of SAS (2008). The mean value was compared using the Duncan Multiple Range Test (DMRT) at $5 \%$ level of significance.

\section{RESULTS AND DISCUSSION}

\section{Phenotypic performance of hilly chickens}

The performance of hilly chickens in three different treatment groups is presented in Table 2. Reddish brown hilly type chicken laid longer period (clutch size) and larger sized egg than the spotted hilly type chicken in all treatments. In addition, egg production, body weight and egg weight of reddish brown hilly were better for artificial lighting group than heat stress and control group. Similar findings were observed by
Lucas et al. (2013) and Deng et al. (2012). Egg weight of both type of hilly chickens was ranged from 40.46 to $43.85 \mathrm{~g}$. The mature live weight of reddish brown type chicken was higher under lighting condition than spotted hilly type chicken. These findings were similar to Khan et al. $(2007,2017)$.

The mortality of the chickens was 13 to 23 percent. The mortality of birds was higher in heat stress group than others (Table 2), the extra percentage of mortality compared to the other group was due to heat stress. In addition to heat stress, the causes of mortality in all groups were the outbreak of diseases: Fowl pox and predator attack in chicken rearing. The hilly people did not treat their diseased chickens. Once in a year the chickens in hilly areas are vaccinated against New castle disease by the Department of Livestock Services (DLS) of the Government of Bangladesh and also by the village poultry workers but this is not regular. Predator problems are common as the housing is near or within the hills and most of the hills are succumbed with predators like fox, wild cat, mongoose etc. Both types of chicken showed broodiness and nesting behavior and hatched their chicks.

Table 2 - Performances of different types of hilly chickens under three treatments.

\begin{tabular}{|c|c|c|c|c|c|c|c|c|}
\hline \multirow{3}{*}{ Parameters } & \multicolumn{6}{|c|}{ Treatment group } & \multirow{3}{*}{ SEM } & \multirow{3}{*}{$p$ value } \\
\hline & \multicolumn{2}{|c|}{ Control } & \multicolumn{2}{|c|}{ Heat stress } & \multicolumn{2}{|c|}{ Light } & & \\
\hline & RB & SBW & $\mathrm{RB}$ & SBW & $\mathrm{RB}$ & SBW & & \\
\hline Egg production (no/Mo/bird) & $7.89^{a}$ & $6.52^{b}$ & $7.96^{a}$ & $6.69^{b}$ & $8.56^{a}$ & $6.83^{b}$ & 0.354 & 0.047 \\
\hline Egg production (no/year) & $94.66^{a}$ & $78.24^{b}$ & $95.52^{\mathrm{a}}$ & $80.28^{b}$ & $102.72^{\mathrm{a}}$ & $81.96^{b}$ & 4.315 & 0.021 \\
\hline Egg weight (g) & $41.52^{b}$ & $41.63^{b}$ & $40.46^{c}$ & $41.77^{\mathrm{ab}}$ & $43.19^{a}$ & $43.21^{\mathrm{a}}$ & 0.531 & 0.001 \\
\hline Live weight (g) & $1454.58^{b}$ & $1366.15^{b c}$ & $1409.99^{b}$ & $1392.26^{b}$ & $1483.13^{\mathrm{a}}$ & $1412.55^{c}$ & 22.45 & 0.016 \\
\hline Clutch Size (d) & $11.07^{\mathrm{ab}}$ & $12.03^{a}$ & $10.87^{\mathrm{ab}}$ & $8.99^{c}$ & $11.76^{a}$ & $9.98^{b}$ & 1.307 & 0.001 \\
\hline Mortality (\%) & $18.70^{\mathrm{b}}$ & $15.15^{b}$ & $19.80^{a}$ & $22.87^{a}$ & $17.93^{b}$ & $13.20^{\mathrm{b}}$ & 2.562 & 0.025 \\
\hline
\end{tabular}

Legends: $\mathrm{RB}=$ Reddish Brown; and SBW= Spotted Black and White

Means with different superscripts are different at $5 \%$ level of significance (in column)

$\mathrm{SEM}=$ Standard error of mean. 


\section{Breed variability and differentiation}

The genetic variability of each type of hilly chicken under the three treatments observed $\left(\mathrm{H}_{\mathrm{O}}\right)$ and expected $\left(\mathrm{H}_{\mathrm{E}}\right)$ heterozygosity, molecular coancestry (fij) and polymorphism information content (PIC) are shown in Table 3. The $\mathrm{Ho}$ and $\mathrm{H}_{\mathrm{E}}$ values of Reddish brown as ranged from 0.67 (light) to 0.81 (control) and 0.43 (Heat) to 0.57 (Light), respectively. For the spotted black and white the $\mathrm{Ho}$ and $\mathrm{H}_{\mathrm{E}}$ values were as 0.75 (Heat) to 0.88 (Control) and 0.33 (Control) to 0.55 (Heat), respectively. From this study, it can be concluded that the observed values were higher than expected for all treatments and chicken types. The high number of monomorphic loci detected may explain the low number of heterozygotes. Values of $\mathrm{H}_{\mathrm{O}}$ was higher than in other studies; however, the values of $\mathrm{H}_{0}$ were similar to the findings of Zanetti et al. (2010). These findings indicated loss of genetic diversity.

Table 3 - Expected $\left(H_{E}\right)$ and observed $\left(H_{0}\right)$ heterozygosity, within-breed molecular coancestry $\left(f_{1 J}\right)$ for each type analyzed and polymorphic information content (PIC).

\begin{tabular}{|c|c|c|c|c|c|c|c|c|c|c|c|c|}
\hline \multirow{3}{*}{ Types } & \multicolumn{12}{|c|}{ Treatment groups } \\
\hline & \multicolumn{4}{|c|}{ Control } & \multicolumn{4}{|c|}{ Heat stress } & \multicolumn{4}{|c|}{ Light } \\
\hline & $\mathrm{H}_{0}$ & $\mathrm{H}_{\mathrm{E}}$ & $\mathrm{PIC}$ & $\mathrm{f}_{\mathrm{iji}}$ & $\mathrm{H}_{0}$ & $\mathrm{H}_{\mathrm{E}}$ & $\mathrm{PIC}$ & fij & $\mathrm{H}_{0}$ & $\mathrm{H}_{\mathrm{E}}$ & $\mathrm{PIC}$ & $f_{i j}$ \\
\hline Hilly RB & 0.75 & $0.50^{\mathrm{b}}$ & $0.63^{a}$ & 0.15 & 0.81 & 0.43 & $0.46^{a}$ & $0.12^{\mathrm{a}}$ & $0.67^{a}$ & $0.57^{b}$ & 0.75 & 0.19 \\
\hline Hilly SBW & 0.88 & $0.33^{\mathrm{a}}$ & $0.86^{b}$ & 0.22 & 0.75 & 0.50 & $0.86^{b}$ & $0.22^{b}$ & $0.87^{b}$ & $0.34^{\mathrm{a}}$ & 0.63 & 0.15 \\
\hline
\end{tabular}

Legend: $\mathrm{RB}=$ Reddish Brown; and SBW= Spotted Black and White

The superscript $a$ and $b$ indicate significant differences between genotypes at $5 \%$ level of significance.

The within-breed molecular coancestry (fij) values for hilly reddish brown type chicken varied from 0.12 to 0.19 and for hilly spotted white chicken varied from 0.15 to 0.22 . This value indicated that these two types of hilly chickens have a minimum genetic differentiation. A similar finding was reported by Tadano et al. (2007) for native Japanese poultry breeds and in contrast with lower genetic differentiation values found in 8 Finnish chicken breeds by Vanhala et al. (1998) and Monira et al. (2011) of a Bangladesh study. The genetic diversity of the two hilly types was also assessed by calculating the polymorphic information content (PIC) values. PIC values vary from 0.46 to 0.75 for reddish brown type chicken and 0.63 to 0.86 for spotted white type chicken, respectively. These PIC values indicated the moderate diversity.

Among the two types of hilly chickens, the reddish brown type produced more eggs than spotted black and white. In addition to egg production, other performance of reddish brown chicken was better than spotted black and white chicken and their genetic diversity was low to moderate. Therefore, the selection of reddish brown type hilly chickens will be the better option for the incorporation of further genetic improvement programs.

\section{ACKNOWLEDGEMENTS}

We would like to express our sincere gratitude to the Ministry of Science and Technology, Government of the People's Republic of Bangladesh for providing the funds under the special allocation for science and technology to implement this project. Thanks to the authority of Chittagong Veterinary and Animal Sciences University, Bangladesh for giving permission to pursue this study. Finally, we thank all the farmers for helping conduct the research in their locality and providing the required data.

\section{REFERENCES}

Amie Marini AB, Hifzan RM, Tan SG, Panandam JM. Assessment of genetic diversity on oat breeds in Malaysia using Microsatellite markers. Malaysian Journal of Animal Science 2014;17:19-26.

Boettcher PJ, Tixier-Boichard M, Toro MA, Simianer H, Eding H, Gandini G, et al. Objectives, criteria and methods for using molecular genetic data in priority setting for conservation of animal genetic resources. Animal Genetics 2010;41:64-77.

Botstein D, White RL, Skolnick M, Davis RW. Construction of a genetic linkage map in man using restriction fragment polymorphysms. American Journal of Human Genetics 1980;32:314-331.

Caballero A, Toro MA. Analysis of genetic diversity for the management of conserved subdivided populations. Conservarion Genetics 2002;3:289299.

Dalvit C, De Marchi M, Cassandro M. Genetic traceability of livestock products: a review. Meat Science 2007;77:437-449.

Deng W, Dong XF, Tong JM, Zahang Q. The probiotic Bacillus licheniformis ameliorates heat stress-induced impairment of egg production, gut morphology, and intestinal mucosal immunity in laying hens. Poultry Science 2012;91:575-582.

Faruque S, Siddiquee NU, Afroz MA, Islam MS. Phenotypic characterization of native chicken reared under intensive management system. Journal of Bangladesh Agricultural University 2010;8:79-82.

Fonteque GV, Battilana, Paludo E, Lima-Rosa CAV. Genetic polymorphism of fifteen microsatellite loci in Brazilian (blue-egg Caipira) chickens. Pesquisa Veterinária Brasiliera 2014;34(1):98-102. 
Khan MKI, Bhuiyan, MSA, Khatun MJ, Dey BC. Phenotypic characterization of hilly chicken of Bangladesh. Progressive Agriculture 2004;15:47-52.

Khan MKI, Debath NC, Bhuiyan MSA, Khatun MJ, Karim MR, Dey BC. Development of crossbred chickens for semi-scavenging system by the crossing of hilly (native) with Rhode Island Red and Fayoumi. Indian Journal of Animal Sciences 2007;77:257-261.

Khan MKI, Siddiki AMAM, Ali MR, Akter MA, Identification of best egg producers' Hilly chicken in consideration of climate change factors:light and heat. Indian Journal of Animal Sciences 2017;87(8):991-995.

Lucas JL, Marcos HR. Impact of heat stress on poultry production. Animals 2013;3:356-369

Monira KN, Islam MN, Khatun R, Ahmed S. Genetic relationship and similarity of some selected chicken strains. Journal of Bangladesh Agricultural University 2011;9(2):217-220.

Nayak GD, Behura NC, Sardar KK, Mishra PK. Effect of climatic variables on production and reproduction traits of coloured broiler breeder poultry. Veterinary World 2015;8:472-477

Nedup D, Monchai D, Yupin P. Genetic characterization of Bhutanese native chickens based on an analysis of Red Jungle fowl (Gallus gallus and Gallus gallus spadecieus), domestic Southeast Asian and commercial chicken lines (Galluas gallus domesticus). Genetics and Molecular Biology 2012;35(3):603-609.
Nakamura A, Nagao K, Watanabe $\mathrm{H}$, Kondo $\mathrm{H}$. Characteristics of PCR fragments amplified using five microsatellite markers for identifying the Nagoya breed. Animal Science Journal 2010;81:438-443.

Star LE, Decuypere H, Parmentier K, Kemp B. Effect of single or combined climatic and hygienic stress in four layer lines: 2. Endocrine and oxidative stress responses. Poultry Science 2008;87:1031-1038

SAS - Statistical Analytical Sofware. Users' guide Ver. 8.12. Cary: SAS Institute; 2008.

Tixier-Boichard M, Bordas A, Rognon X. Characterization and monitoring of poultry genetic resources. World Poultry Science Journal 2009;65:272285.

Tadano R, Nishibori M, Nagasaki N, Tsudzuki M. Assessing genetic diversity and population structure for commercial chicken lines based on forty microsatellite analysis. Poultry Science 2007;86:513-546.

Vanhala T, Tuiskula-Haavisto M, Elo K, Vilkki J, Maki-Tanila A. Evaluation of genetic variability and genetic distances between chicken lines using microsatellite markers. Poultry Science 1998;77:783-790.

Zanetti E, Marchi M, Dalvit CD, Cassandro M. Genetic characterization of local Italian breeds of chickens undergoing in situ conservation. Poultry Science 2010;89:420-427. 
